\title{
Risk Factors of Underweight in Children Aged 6-59 Months in Ethiopia
}

\author{
Deneke Tosheno, ${ }^{1}$ Yohannes Mehretie Adinew, ${ }^{2}$ \\ Thilagavathi Thangavel, ${ }^{2}$ and Shimelash Bitew Workie ${ }^{2}$ \\ ${ }^{1}$ Wolaita Zonal Health Department, Sodo, Ethiopia \\ ${ }^{2}$ College of Health Sciences and Medicine, Wolaita Sodo University, Sodo, Ethiopia \\ Correspondence should be addressed to Yohannes Mehretie Adinew; yohannes1979@gmail.com
}

Received 25 June 2017; Revised 7 October 2017; Accepted 16 October 2017; Published 13 November 2017

Academic Editor: C. S. Johnston

Copyright (C) 2017 Deneke Tosheno et al. This is an open access article distributed under the Creative Commons Attribution License, which permits unrestricted use, distribution, and reproduction in any medium, provided the original work is properly cited.

\begin{abstract}
Background. Undernutrition in early childhood has irreversible and long-lasting implications. Hence, this study was aimed at assessing risk factors of child undernutrition. Methods. A community-based cross-sectional study was conducted on 642 households with mothers to children pairs aged 6-59 months selected by a multistage systematic random sampling method. Child anthropometric measurements on weight were recorded using standardized and calibrated weighing scales. Weight-for-age was compared to the 2007 WHO growth reference by WHO Anthro software. Data were entered using Epi-Info and analyzed using SPSS. Bivariate and multivariate logistic regression analyses were used to evaluate the association between underweight children and their predictors; both crude and adjusted odds ratios with $95 \%$ confidence interval were reported. Results. One-fourth (25\%) of the children were underweight. Child age (AOR: 2.36), gender (AOR: 1.82), illness (AOR: 0.09), maternal decision making power (AOR: 0.07), maternal education (AOR: 0.19), employment/occupation (AOR: 5.29), and household income (AOR: 4.16) were found to be independent and significant predictors of underweight children. Conclusion. Significant proportion of the children were underweight. Maternal decision-making power persists as a strong predictor of children's weight. Therefore, intervention programs focusing on improving mothers' decision-making power on child nutrition would contribute to the efforts towards alleviating the problem.
\end{abstract}

\section{Background}

Undernutrition is still a prevailing evil affecting under-five children in the developing world [1]. Its consequences are severe and have irreversible and long-lasting implications [2]. It is responsible for the annual deaths of 3.5 million underfive children globally and the third disease burden of this age group. It continues to be a significant global public health and development concern [3].

Globally, an estimated $16 \%$ of under-five children were underweight (i.e., weight-for-age below -2 SD) in 2011. The estimated prevalence of underweight in 2011 was $17.7 \%$ in Africa, 21.4\% in Sub-Saharan Africa, and 19.3\% in East Africa $[4,5]$. More than $25 \%$ of under-five children in the developing world are malnourished. Among these malnourished children, nearly three-quarters live in just 10 countries of Sub-Saharan Africa region; Ethiopia and Nigeria alone share $33 \%$ of the region's burden [6].

In Ethiopia, large proportions of children have been suffering from undernutrition. According to the 2014 Ethiopian Mini Demographic and Health Survey (EDHS) [7], 25\% of under-five children were underweight and among those $7 \%$ were severely underweight. As to the south region, the prevalence of underweight is comparable to the national level with $25.7 \%$ underweight and $7.9 \%$ severe underweight. This shows that child malnutrition is still a critical problem in Ethiopia.

Moreover, in identifying causes and determinants of child underweight, little research has addressed the association between women's decision-making power and child 
underweight, which reflects both cumulative and acute exposures to malnutrition in Ethiopia in general and as a study-setting in particular. Therefore, this study focuses on examining the association between children's underweight and mothers' decision-making power.

\section{Methods and Materials}

2.1. Study Design and Area. A community-based crosssectional study was conducted in Wolaita Sodo town. Wolaita Sodo is located $385 \mathrm{~km}$ to the south of the capital Addis Ababa. According to the 2007 Ethiopian national population and housing census, the population of the town was projected to be about 137,522 in July 2014 , with a $1.03: 1$ male to female ratio [8]. The town was structured into 3 sub-cities and 11 kebeles (the smallest administrative unit). There were 2 hospitals, 3 health centers, 11 health posts, and 21 private clinics. The main staple food of the population was teff and maize.

2.2. Source Population and Sample Size Determination. Source population was all children aged 6-59 months and their mothers in Wolaita Sodo town. All selected children aged 6-59 months and their mothers living in selected kebeles of Wolaita Sodo town were study population. Sample size was determined by using a single population proportion formula with the assumptions of $95 \% \mathrm{CI}, 5 \%$ of margin of error, reported prevalence of underweight among under-five children in the southern region to be $25.7 \%$ [5], design effect 2 , and $10 \%$ possible nonresponse rate, which gives the total sample size of 642 .

2.3. Inclusion and Exclusion Criteria. All children aged 6-59 months and their mothers who were permanent residents of selected kebeles and households were included. Children who were seriously ill or had edema and physical deformities of limbs and spines were excluded because of difficulty in anthropometric measurements. Children whose mothers were severely sick and unable to respond were also excluded.

2.4. Sampling Technique. A multistage systematic random sampling technique was used. First, out of 11 kebeles in Sodo town, 5 were randomly selected. Data from the town health offices and health posts on a number of households with children aged 6-59 months were identified for the randomly selected kebeles. The total sample size was proportionally allocated to the size of children aged 6-59 months in the selected kebeles. Systematic random sampling technique was employed to select the households/mothers and children aged 6-59 months enrolled in the study. Sampling interval was calculated by dividing total study population in the selected kebeles by the number of sample units $(N / n)$, which was $6760 / 642 \approx 10$. The first household was selected within the sampling interval of (1-10) by drawing a random number. Then the sample was taken from every 10th house of the selected kebeles until the required sample size was obtained.

\subsection{Variables Measurement and Definition}

2.5.1. Dependent Variable. Children with $Z$ score of less than -2 were categorized underweight, whereas those with -2 or above were categorized normal as per $\mathrm{WHO} z$ score.

2.5.2. Independent Variables. Socioeconomic and demographic factors sex, age, family size, monthly average income, maternal education, decision-making power, occupation and marital status, child dietary intake, and health related disease factors were among the independent variables. Mothers' decision-making power in the household was measured by asking them eight items. For each item, the response was scored 2 if a woman made a sole decision, 1 if she was involved with a husband/partner or someone else, and 0 for otherwise. The sum of the scores was made to represent an overall index of a woman's decision-making power as indicated by previous studies $[9,10]$. The total maximum score of decision-making power was 16 and the minimum was 0 . Hence, those women who scored eight and above were categorized as women with high decision-making power, whereas those who scored less than eight were categorized as women with low decisionmaking power.

2.6. Data Collection and Quality Control. Pre-tested structured questionnaire was used for interviews, and a digital portable calibrated SECA weighing scale was used for anthropometric measurements. Data were collected by eight experienced diploma-holding nurses. Two senior nurses supervised the data collection.

Weight of children was measured by using the standard digital SECA scale to the nearest $0.1 \mathrm{~kg}$. For weight measurement study, participants removed their shoes and jackets and wore light clothing. For children less than 2 years old and who did not stand still or those who jumped, tarred weighing was done. The age of the children was confirmed from the birth certificate or the child's immunization card, if any, or by asking the mother. If the mother could not remember the child's age, it was probed and local events were used to assist the mother.

A two-day-training was given to data collectors and supervisors on the tool, interviewing skills, and the use of weight scale, in order to minimize inter- and intraobserver errors. Technical error of measurement (TEM) was computed during training. For this, an expert took two weight measurements of ten children and let the data collectors take the measurements of all ten children twice. Then, the data was entered and computed by ENA SMART software and was confirmed acceptable. Weighing scale was calibrated to zero before taking every measurement. Measurement of weight was taken in duplicate for each child. The questionnaire was pretested in $5 \%$ of households selected from kebeles not included in the study, and some modifications were made based on response categories. To improve the quality of data, data collectors were closely supervised; each completed questionnaire was checked to ascertain all questions were properly filled and corrected by a principal investigator on daily basis. 
2.7. Data Processing and Analysis. Data were coded and entered into Epi-Info version 3.5.4 and WHO Anthro version 3.2.2 software and exported to SPSS version 20 for further analysis. Continuous variables were checked for normality using Kolmogorov-Smirnov test. Descriptive statistics were done. Hosmer-Lemeshow test was performed for model fitness, and multicollinearity was also checked using variance inflation factor and correlation coefficients. Bivariate and multivariate logistic regression analyses were used to evaluate the association between children's underweight and predictor variables; adjusted odds ratios with 95\% confidence interval were reported. Statistical significance was considered at $P$ value less than 0.05 .

\section{Results}

3.1. Sociodemographic Characteristics. A total of 642 (100.0\%) questionnaires were eligible for analysis. Nearly two-thirds, $437(68.4 \%)$, of the children were in the age category of $25-34$ months and $51.9 \%$ of them were boys. The majority of the respondents, $386(60.1 \%)$ and $463(72.1 \%)$, were protestant in religion and Wolaita in their ethnicity, respectively. About $85 \%$ of the respondents had formal education, $306(47.7 \%)$ were housewives, and 615 (95.8\%) were married. Nearly half, 304 , of them $(47.4 \%)$ had less than five as a family size. Forty two percent of the respondents had less than 2000-birr average monthly income (Table 1 ).

3.2. Health, Feeding Practice, and Dietary Intake of Children and Prevalence of Underweight. Mean dietary diversity score for study participants was 5.05. About 132 (20.6\%) of study participants had a poor dietary diversity (DDS $\leq 3)$ and another $380(59.2 \%)$ had a medium dietary diversity score (DDS 4-6), whereas 130 (20.2\%) of study participants had a good dietary diversity score, DDS $\geq 7$. The majority, 513 (79.9\%), of the mothers had timely initiated complementary food for their children. Only 117 (18.2\%) children experienced sickness during the last two weeks prior to data collection. Prevalence of the underweight was found to be $158(24.6 \%)$ with 95\% CI $(21.3 \%, 27.9 \%), 126$ (19.6\%) moderate, and 32 $(5.0 \%)$ severe. The prevalence of underweight was more in male children $92(27.6 \%)$ compared to their female counterparts, 66 (21.4\%) (Table 2).

3.3. Household Decision-Making Power/Autonomy of Mothers. Among the eight decision-making items, the sole involvement of women was more in foods to be given to children, $401(62.5 \%)$, and the purchase of small household needs, 272 (42.4\%). Women hold very low decision-making power in large household purchases, 44 (6.9\%). More than half of the women had joint involvement regarding large household purchases, 325 (50.6\%), child health care, 361 (56.2\%), using contraceptive methods, 505 (78.7\%), participating in money earning works, $440(68.5 \%)$, and when and where to take sick child leave for treatment, 420 (65.4\%). Decision-making index showed that $71.1 \%$ of women had high decision-making power on the household decisions (Table 3).
TABLE 1: Sociodemographic characteristics of respondents in Wolaita Sodo town, southern Ethiopia, 2016.

\begin{tabular}{|c|c|c|}
\hline Variables $(n=642)$ & Frequency $(N)$ & Percentage (\%) \\
\hline \multicolumn{3}{|l|}{ Age of the children } \\
\hline 6-11 months & 63 & 9.8 \\
\hline $12-23$ months & 175 & 27.3 \\
\hline 24-35 months & 165 & 25.7 \\
\hline 36-47 months & 132 & 20.6 \\
\hline $48-59$ months & 107 & 16.7 \\
\hline \multicolumn{3}{|l|}{ Sex of the children } \\
\hline Male & 333 & 51.9 \\
\hline Female & 309 & 48.1 \\
\hline \multicolumn{3}{|l|}{ Educational status } \\
\hline No formal education & 107 & 16.7 \\
\hline Primary education & 287 & 44.7 \\
\hline Secondary education & 98 & 15.3 \\
\hline Diplomas and higher education & 150 & 23.4 \\
\hline \multicolumn{3}{|l|}{ Occupation } \\
\hline Housewife & 306 & 47.7 \\
\hline GOE/NGOE & 208 & 32.4 \\
\hline Merchant & 106 & 16.5 \\
\hline Others & 22 & 3.4 \\
\hline \multicolumn{3}{|l|}{ Household family size } \\
\hline$<5$ & 304 & 47.4 \\
\hline $5+$ & 338 & 52.6 \\
\hline \multicolumn{3}{|l|}{ Average monthly income } \\
\hline$\leq 2000$ & 275 & 42.8 \\
\hline $2001-4000$ & 264 & 41.1 \\
\hline$>4000$ & 103 & 16.0 \\
\hline
\end{tabular}

3.4. Factors Associated with Underweight. In multivariate logistic analysis, children of 24-45 months age group were 2.36 times $(\mathrm{AOR}=2.36,95 \% \mathrm{CI}(1.03-5.4))$ more likely to be underweight compared to children who were in an age group of 48-59 months. Male children were 1.8 times (AOR $=1.82,95 \%$ CI (1.07-3.09)) more likely to be underweight than females. Children whose mothers had only secondary education were $81 \%$ more $(\mathrm{AOR}=0.19,95 \%$ CI $(0.05-0.73))$ likely to be underweight than those whose mothers had diplomas and above. Children whose mothers' occupations were housewives were 3.26 times $(\mathrm{AOR}=3.26$, 95\% CI (1.06-9.99)) more likely to be underweight than those of employees. Children from families whose monthly income was 4000.00 ETB and below were about four times (AOR $=4.16$, 95\% CI (1.57-11.05)) more likely to be underweight than those who had above 4000.00 ETB. Children who did not experience illness for the last two weeks prior to the survey were $91 \%$ less likely to be underweight than those who were sick $(\mathrm{AOR}=0.09,95 \% \mathrm{CI}(0.05-0.16))$. The odds of getting underweight among children whose mothers had high decision-making power decreased by $93 \%$ when compared to children whose mothers had low decision-making 
TABLE 2: Prevalence of underweight among children aged 6-59 months in Wolaita Sodo town, southern Ethiopia, 2016.

\begin{tabular}{|c|c|c|}
\hline Variables $(n=642)$ & Frequency $(N)$ & Percentage (\%) \\
\hline Normal (WAZ $\geq-2$ SD) & 412 & 64.2 \\
\hline Moderate underweight (WAZ $\geq-3$ SD \& $<-2$ SD) & 126 & 19.6 \\
\hline Severe underweight $(\mathrm{WAZ}<-3 \mathrm{SD})$ & 32 & 5.0 \\
\hline Total of underweight children & 158 & 24.6 \\
\hline \multicolumn{3}{|l|}{ Underweight by sex } \\
\hline \multicolumn{3}{|l|}{ Male } \\
\hline Moderate & 70 & 21.0 \\
\hline Severe & 22 & 6.6 \\
\hline Total & 92 & 27.6 \\
\hline \multicolumn{3}{|l|}{ Female } \\
\hline Moderate & 56 & 18.2 \\
\hline Severe & 10 & 3.2 \\
\hline Total & 66 & 21.4 \\
\hline \multicolumn{3}{|l|}{ Underweight by age } \\
\hline 6-11 months & 21 & 33.3 \\
\hline $12-23$ months & 44 & 25.1 \\
\hline $24-36$ months & 45 & 27.3 \\
\hline $37-47$ months & 33 & 25.0 \\
\hline 48-59 months & 15 & 14.0 \\
\hline
\end{tabular}

power $(\mathrm{AOR}=0.07,95 \% \mathrm{CI}(0.04-0.12))$ after controlling for other variables. The proportion of underweight children is higher $(63.2 \%)$ in mothers who had low decision-making power compared to mothers who had high decision-making power (9.3\%) (Table 4).

\section{Discussion}

A quarter $(24.6 \%)$ of the children were underweight, indicating high magnitude of undernutrition in the study area [11]. This finding is comparable with the national (25\%) and regional (25.7\%) levels [7] as well as the finding of the study from Lalibela [12]. However, this prevalence was lower compared to the prevalence reported by a number of other studies conducted in developing countries and different parts of Ethiopia [13-20]. The difference might be that this study includes only urban setup, whereas the other studies include also rural areas.

In multivariate logistic analysis, maternal decisionmaking power, educational status and occupation of mother, monthly income of the household, age and sex of child, and child illness remain significantly associated with underweight.

The odds of getting underweight among children whose mothers had high decision making power decreased by $93 \%$ compared to children whose mothers had low decisionmaking power. This finding was in-line with EDHS 2011 [21], which indicated that children whose mothers participated in decision-making have 0.035 higher units of nutritional status than those whose mothers did not. The finding was also similar to a study from Bangladesh [22], International Food
Policy Research Institute's report [23], and Egypt [24], which inferred that women's decision-making power is significant and has positive effect on height-for-age, weight-for-height, and weight-for-age. Mothers with high decision-making power have control within their households of accessing resources, behaving independently, and being able to act in a manner that best promotes the survival and growth of their children [25].

Male children were 1.8 times more likely to be underweight than females. This result is consistent with results of studies conducted in different parts of Ethiopia, Bule Hora [26] and Dollo Ado [27] districts as well as Vietnam [28]. This might be explained by the fact that boys are more influenced by environmental stress than girls [28]; but more prospective cohort studies are warranted.

Increased maternal educational status had a protective effect. The odds of getting underweight among mothers who had diplomas and higher educational statuses decreased by $81 \%$ more than mothers who had only secondary education. The finding was consistent with a study conducted in Ethiopia $[29,30]$. The possible explanation could be that mothers who had better education had better income and better childcare practice.

Children from families whose monthly income was 4000.00 ETB and below were more likely to be underweight than those who had families with income greater than 4000.00 ETB. This result is in-line with the WHO indicators report, which shows that families with higher monthly per capita income had significantly lower prevalence of underweight children [31], which is also supported by different studies in different parts of Ethiopia like the southern region 
TABLE 3: Household decision-making autonomy of mothers in Wolaita Sodo town, southern Ethiopia, 2016.

\begin{tabular}{|c|c|c|}
\hline Variables $(n=642)$ & Frequency & Percentage \\
\hline \multicolumn{3}{|l|}{ Decision-making on small household purchases } \\
\hline Respondent alone & 272 & 42.4 \\
\hline Jointly & 277 & 43.1 \\
\hline Husband and another person/someone else & 7 & 1.1 \\
\hline Husband alone & 86 & 13.4 \\
\hline \multicolumn{3}{|l|}{ Decision-making on large household purchases } \\
\hline Respondent alone & 44 & 6.9 \\
\hline Jointly & 325 & 50.6 \\
\hline Husband and another person/someone else & 8 & 1.3 \\
\hline Husband alone & 265 & 41.5 \\
\hline \multicolumn{3}{|l|}{ Decision-making on mother and child healthcare } \\
\hline Respondent alone & 141 & 22.0 \\
\hline Jointly & 361 & 56.2 \\
\hline Husband and another person/someone else & 7 & 1.1 \\
\hline Husband alone & 133 & 20.7 \\
\hline \multicolumn{3}{|c|}{ Decision-making on right quantity and type of foods to be given to children } \\
\hline Respondent alone & 401 & 62.5 \\
\hline Jointly & 172 & 26.8 \\
\hline Husband and another person/someone else & 5 & 0.8 \\
\hline Husband alone & 64 & 10.0 \\
\hline \multicolumn{3}{|l|}{ Decision-making on family planning } \\
\hline Respondent alone & 68 & 10.6 \\
\hline Jointly & 505 & 78.7 \\
\hline Husband and another person/someone else & 3 & 0.5 \\
\hline Husband alone & 66 & 10.3 \\
\hline \multicolumn{3}{|c|}{ Decision-making on participating on work to earn money } \\
\hline Respondent alone & 46 & 7.2 \\
\hline Jointly & 440 & 68.5 \\
\hline Husband and another person/someone else & 4 & 0.6 \\
\hline Husband alone & 152 & 23.7 \\
\hline \multicolumn{3}{|l|}{ Decision-making on sick child treatment } \\
\hline Respondent alone & 71 & 11.1 \\
\hline Jointly & 420 & 65.4 \\
\hline Husband and another person/someone else & 4 & 0.6 \\
\hline Husband alone & 147 & 22.9 \\
\hline \multicolumn{3}{|c|}{ Summary of maternal decision-making power matrix } \\
\hline Low & 182 & 28.3 \\
\hline High & 460 & 71.7 \\
\hline
\end{tabular}

[27] and Dollo Ado [15]. Wealthy families can get enough food for their children, as a result underweight is unlikely.

Children who did not experience any illness in the last two weeks prior to the survey had a $91 \%$ decreased chance of being underweight than those who were ill. Similar studies had also found significant association between the presence of diarrhea within the last two weeks before the survey and underweight in children $[15,26,32]$. As diarrhea depletes the body fluids, children with diarrhea are more likely to lose weight and show low weight for their ages [33].

\section{Conclusion}

The prevalence of undernutrition among the children was found to be high. Maternal decision-making power has significant association with children's weight. Thus, 
TABLE 4: Bivariate and multivariate analyses of Sociodemographic characteristics of study participants in Sodo town, southern Ethiopia, 2016.

\begin{tabular}{|c|c|c|c|c|}
\hline \multirow{2}{*}{ Variables $(n=642)$} & \multicolumn{2}{|c|}{ Underweight } & \multirow{2}{*}{ COR $(95 \% \mathrm{CI})$} & \multirow{2}{*}{$\operatorname{AOR}(95 \% \mathrm{CI})$} \\
\hline & No $(\%)$ & Yes $(\%)$ & & \\
\hline \multicolumn{5}{|l|}{ Age of the children } \\
\hline 6-11 months & $42(66.7 \%)$ & $21(33.3 \%)$ & $3.07(1.44-6.53)^{*}$ & $2.05(0.74-5.69)$ \\
\hline $12-23$ months & $131(74.9 \%)$ & $44(25.1 \%)$ & $2.06(1.08-3.92)^{*}$ & $2.30(0.99-5.32)$ \\
\hline 24-35 months & $120(72.7 \%)$ & $45(27.3 \%)$ & $2.30(1.21-4.38)^{*}$ & $2.36(1.03-5.43)^{*}$ \\
\hline 36-47 months & $99(75.0 \%)$ & $33(25.0 \%)$ & $2.04(1.04-4.01)^{*}$ & $2.35(0.97-5.69)$ \\
\hline $48-59$ months & $92(86.0 \%)$ & $15(14.0 \%)$ & 1 & 1 \\
\hline \multicolumn{5}{|l|}{ Sex } \\
\hline Male & $241(72.4 \%)$ & $92(27.6 \%)$ & $1.4(.98-2.02)$ & $1.82(1.07-3.09)^{*}$ \\
\hline Female & $243(78.6 \%)$ & $66(21.4 \%)$ & 1 & 1 \\
\hline \multicolumn{5}{|l|}{ Educational status } \\
\hline No formal & $52(48.6 \%)$ & $55(51.4 \%)$ & $9.5(4.95-18.31)^{*}$ & $0.88(0.23-3.33)$ \\
\hline Primary & $208(72.5 \%)$ & $79(27.5 \%)$ & $3.4(1.89-6.19)^{*}$ & $0.42(0.13-1.43)$ \\
\hline Secondary & $89(90.8 \%)$ & $9(9.2 \%)$ & $0.91(0.38-2.17)$ & $0.19(0.05-0.73)^{*}$ \\
\hline Diplomas \& higher education & $135(90.0 \%)$ & $15(10.0 \%)$ & 1 & 1 \\
\hline \multicolumn{5}{|l|}{ Occupation } \\
\hline GOE/NGOE & $192(92.3 \%)$ & $16(7.7 \%)$ & 1 & 1 \\
\hline Housewife & $197(64.4 \%)$ & $109(35.6 \%)$ & $6.6(3.79-11.64)^{*}$ & $3.26(1.06-9.99)^{*}$ \\
\hline Merchant & $80(75.5 \%)$ & $26(24.5 \%)$ & $3.9(1.99-7.66)^{*}$ & $5.29(1.58-17.70)^{*}$ \\
\hline Daily laborer & $10(62.5 \%)$ & $6(37.5 \%)$ & $7.2(2.32-22.36)^{*}$ & $2.04(0.31-13.43)$ \\
\hline Others & $5(83.3 \%)$ & $1(16.7 \%)$ & $2.4(0.26-21.81)$ & $2.52(0.15-43.18)$ \\
\hline \multicolumn{5}{|l|}{ Average monthly income } \\
\hline$\leq 2000$ & $182(66.2 \%)$ & $93(33.8 \%)$ & $12.6(4.51-35.44)^{*}$ & $2.38(0.85-6.69)$ \\
\hline $2001-4000$ & $203(76.9 \%)$ & $61(23.1 \%)$ & $7.4(2.63-21.04)^{*}$ & $4.16(1.57-11.05)^{*}$ \\
\hline$>4000$ & $99(96.1 \%)$ & $4(3.9 \%)$ & 1 & 1 \\
\hline \multicolumn{5}{|c|}{ Time of introducing complementary food } \\
\hline Before 6 months & $79(61.2 \%)$ & $50(38.8 \%)$ & $2.4(1.57-3.59)^{*}$ & $1.06(0.57-1.98)$ \\
\hline 6-8 months & $405(78.9 \%)$ & $108(21.2 \%)$ & 1 & 1 \\
\hline \multicolumn{5}{|l|}{ Child illness in the last two weeks } \\
\hline No & $445(84.8 \%)$ & $80(15.2 \%)$ & $0.09(0.06-0.14)^{*}$ & $0.09(0.05-0.16)^{* *}$ \\
\hline Yes & $39(33.3 \%)$ & $78(66.7 \%)$ & 1 & 1 \\
\hline \multicolumn{5}{|l|}{ DDS } \\
\hline Poor DDS (1-3) & $71(53.8 \%)$ & $61(46.2 \%)$ & $4.50(2.49-7.96)^{*}$ & $1.54(0.65-3.62)$ \\
\hline Med DDS (4-6) & $304(80.0 \%)$ & $76(20.0 \%)$ & $1.30(0.76-2.21)$ & $0.70(0.34-1.45)$ \\
\hline Good DDS (7+) & $109(83.8 \%)$ & $21(16.2 \%)$ & 1 & 1 \\
\hline \multicolumn{5}{|l|}{ Maternal decision-making power } \\
\hline Low & $67(36.8 \%)$ & $115(63.2 \%)$ & 1 & 1 \\
\hline High & $417(90.7 \%)$ & $43(9.3 \%)$ & $0.06(0.04-0.09)^{*}$ & $0.07(0.04-0.12)^{* *}$ \\
\hline
\end{tabular}

${ }^{*}$ Significant at $P$ value $<0.05 ;{ }^{* *}$ significant at $P$ value $<0.001$.

improving mothers' household decision-making autonomy had a significant influence on children's nutritional status.

\section{Abbreviations}

DDs: Dietary diversity score

EDHS: Ethiopian Demographic and Health Survey

HHs: Households

SNNPR: Southern Nation National and People Region

WAZ: Weight for age $Z$ score

WHO: World Health Organization.

\section{Data Access}

The datasets analyzed during the current study are available with the corresponding author on reasonable request.

\section{Ethical Approval}

Ethical clearance was obtained from the Wolaita Sodo University, the College of Health Sciences, and Medicine Institutional Research Ethics Review Committee. The official letter of cooperation was given to Wolaita zone health offices. 


\section{Consent}

Prior to data collection, the interviewers had explained the objective, benefit, and risks of the study to get informed written consent for the mothers or the caregivers of the children. The right of the respondent to withdraw from the interview or not to participate was respected. Identification of an informant was possible only through specific identification numbers. Data collectors gave advice to the mothers or the caregivers of the undernourished children to provide additional balanced diets for their children and visit nearby health facilities.

\section{Disclosure}

Wolaita Sodo University paid per diem for data collectors.

\section{Conflicts of Interest}

The authors declare that they have no conflicts of interest.

\section{Authors' Contributions}

Deneke Tosheno wrote the proposal, participated in data collection, and analyzed the data. Yohannes Mehretie Adinew and Thilagavathi Thangavel approved the proposal with some revisions, participated in data analysis, and revised subsequent drafts of the paper. Shimelash Bitew Workie wrote up the manuscript. All authors read and approved the final manuscript.

\section{Acknowledgments}

The authors would like to acknowledge Wolaita Sodo University for financial support and study participants for responding to their questionnaire.

\section{References}

[1] D. L. Pelletier, E. A. Frongillo Jr., D. G. Schroeder, and J.P. Habicht, "The effects of malnutrition on child mortality in developing countries," Bulletin of the World Health Organization, vol. 73, no. 4, pp. 443-448, 1995.

[2] L. E. Caulfield, M. de Onis, M. Blossner, and R. E. Black, "Under nutrition as an underlying cause of child deaths associated with diarrhea, pneumonia, malaria and measles," The American Journal of Clinical Nutrition, vol. 80, no. 1, pp. 193-198, 2004.

[3] R. E. Black, L. H. Allen, Z. A. Bhutta et al., "Maternal and child undernutrition: global and regional exposures and health consequences," The Lancet, vol. 371, no. 9608, pp. 243-260, 2008.

[4] S. Setboonsarng, Child malnutrition as a poverty indicator: An evaluation in the context of different development interventions in Indonesia. 2005, ADB Institute Discussion Papers.

[5] United Nations Children's Fund, World Health Organization, The World Bank. UNICEF WHO-2012, World Bank Joint Child Malnutrition Estimates. New York, Geneva, Washington DC: UNICEF, WHO, The World Bank.

[6] UNICEF, The state of the world's children 2008: Child survival, Vol. 8. 2007: Unicef.
[7] 2014, CSA (Central Statistical Agency), Ethiopia Mini Demographic and Health Survey, Addis Ababa: CSA.

[8] 2007, Central Statistics Authority: 2007 Population and Housing Census of Ethiopia, Addis Ababa: Central Statistics Authority.

[9] D. R. Acharya, J. S. Bell, P. Simkhada, E. R. Van Teijlingen, and P. R. Regmi, "Women's autonomy in household decision-making: A demographic study in Nepal," Reproductive Health, vol. 7, no. 1, article no. 15, 2010.

[10] S. Saleem and M. Bobak, "Women's autonomy, education and contraception use in Pakistan: a national study," Reproductive Health, vol. 2, no. 1, article 8, 2005.

[11] 2010, WHO, Nutrition Landscape Information System, Country profile: interpretation guide, Geneva, Switzerland.

[12] B. M. Yalew, "Prevalence of malnutrition and associated factors among children age 6-59 months at lalibela town administration, North WolloZone, Anrs, Northern Ethiopia," Journal of Nutritional Disorders \& Therapy, vol. 4, no. 1, p. 132, 2014.

[13] V. P. Sapkota and C. K. Gurung, "Prevalence and Predictors of Underweight, Stunting and Wasting in Under-five Children," in Nepal Health Research Council, vol. 7, pp. 120-126, 7, 2009.

[14] S. Demissie and A. Worku, "Magnitude and factors associated with malnutrition in children 6-59 months of age in pastoral community of Dollo Ado district, Somali region, Ethiopia," Science Journal of Public Health, vol. 1, no. 4, pp. 175-183, 2013.

[15] K. Mengistu, K. Alemu, and B. Destaw, "Prevalence of malnutrition and associated factors among children aged 6-59 months at hidabu abote district, north shewa, Oromia regional state," Journal of Nutritional Disorders \& Therapy, vol. T1, article 001, 2013.

[16] E. Kebede, Prevalence and determinants of child malnutrition in Gimbi district [M.S. thesis], 2007.

[17] G. Asres and A. I. Eidelman, "Nutritional assessment of ethiopian beta-israel children: a cross-sectional survey," Breastfeeding Medicine, vol. 6, no. 4, pp. 171-176, 2011.

[18] T. F. Gelano, N. Birhan, and M. Mekonnen, "Prevalence of undernutriton and its associated factors among under-five children in Gonder city, NorthWest Ethiopia," Journal of Harmonized Research in Medical Health Science, vol. 2, no. 4, pp. 163-174, 2015.

[19] T. Wolde, B. Tefera, and B. Tadesse, "Prevalence of Undernutrition and Determinant Factors among Preschool Children in Hawassa, Southern Ethiopia," International Journal of Food Science \& Technology, vol. 29, pp. 65-72, 2012.

[20] D. Desalegn, G. Egata, and Y. Halala, "Prevalence of stunting and associated factors among children aged 6 to 59 months in Areka town, Wolaita Zone, Southern Ethiopia," Journal of Biology, Agriculture and Healthcare, vol. 7, no. 1, 2017.

[21] CSA [Ethiopia] and ICF International: Ethiopia Demographic and Health Survey 2011. 2012, Addis Ababa Ethiopia and Calverton, Maryland, USA: Central statistical Agency and ICF International.

[22] P. Bhagowalia, A. R. Quisumbing, P. Menon, and V. Soundararajan, What dimensions of women's empowerment matter most for child nutrition?" evidence using nationally representative data from Bangladesh. IFPRI Discussion Paper 01192. Washington, DC: International Food Policy Research Institute, 2012.

[23] T. Alemu, G. Asgedom, J. Liebenberg, J. Seager, B. Tefera, and T. Woldehanna, 2003, Young Lives Preliminary Country Report: Ethiopia.

[24] "Ubino, Heather, "Mother's Decision Making Power, Attitudes About Self, and Child ealth: Egypt 2008" (2014). Electronic Theses, Treatises and Dissertations, Paper 8880, 2014". 
[25] E. K. Brunson, B. Shell-Duncan, and M. Steele, "Women's autonomy and its relationship to children's nutrition among the Rendille of northern Kenya," American Journal of Human Biology, vol. 21, no. 1, pp. 55-64, 2009.

[26] M. Asfaw, M. Wondaferash, M. Taha, and L. Dube, 2015, Prevalence of under nutrition and associated factors among children aged between six to fifty nine months in Bule Hora district, South Ethiopia. BMC Public Health.

[27] G. Medhin, C. Hanlon, M. Dewey et al., "Prevalence and predictors of undernutrition among infants aged six and twelve months in Butajira, Ethiopia: The P-MaMiE Birth Cohort," BMC Public Health, vol. 10, article 27, 2010.

[28] T. W. Hailemariam, "Prevalence of underweight and its determinant factors of under two children in a rural area of western ethiopia," Food Science and Quality management, vol. 51, pp. 5969, 2014.

[29] A. Habtamu, “2014, The Role of Women's Status on Children's Nutrition Security in Ethiopia, Addis Ababa University, Addis Ababa Ethiopia".

[30] M. Wolde, Y. Berhan, and A. Chala, "Determinants of underweight, stunting and wasting among schoolchildren," $B M C$ Public Health, vol. 15, no. 1, article 8, 2015.

[31] A. Imdad, M. Y. Yakoob, and Z. A. Bhutta, "Impact of maternal education about complementary feeding and provision of complementary foods on child growth in developing countries," BMC Public Health, vol. 11, no. 3, article no. S25, 2011.

[32] M. Alemayehu, F. Tinsae, K. Haileslassie, Seid O., Gebregziabher G., and Yebyo H., "Undernutrition status and associated factors in under-5 children, in Tigray, Northern Ethiopia," Nutrition, vol. 31, no. 7-8, pp. 964-970, 2015.

[33] 2012, UNICEF (United Nations Children's Fund). The State of the World's Children, New York. 


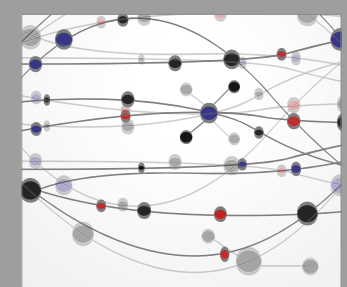

The Scientific World Journal
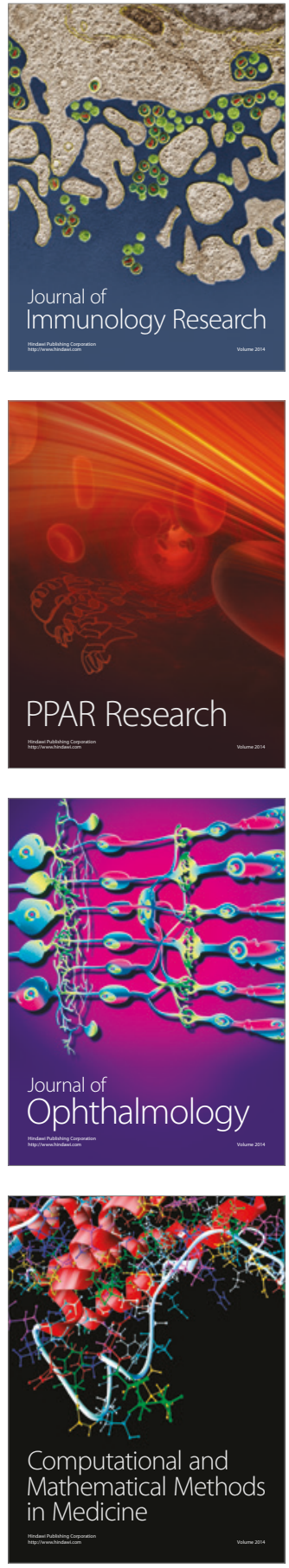

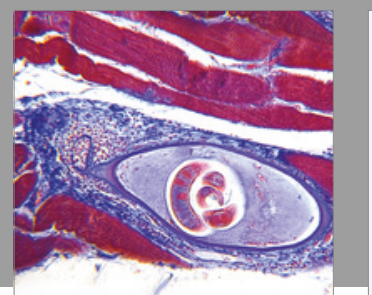

Gastroenterology Research and Practice
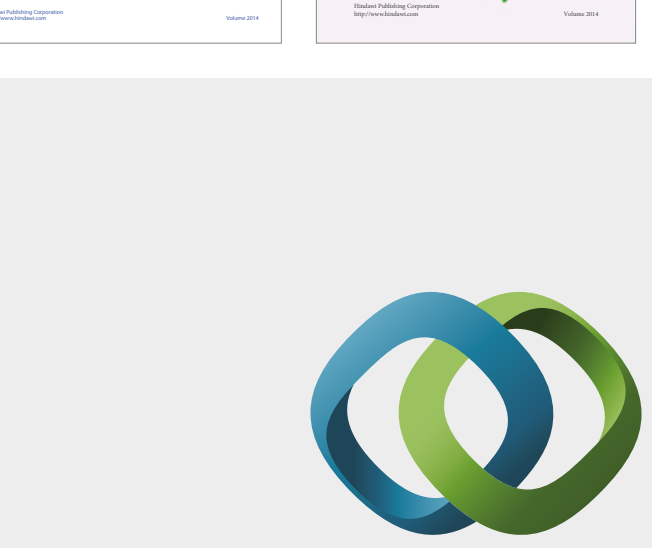

\section{Hindawi}

Submit your manuscripts at

https://www.hindawi.com
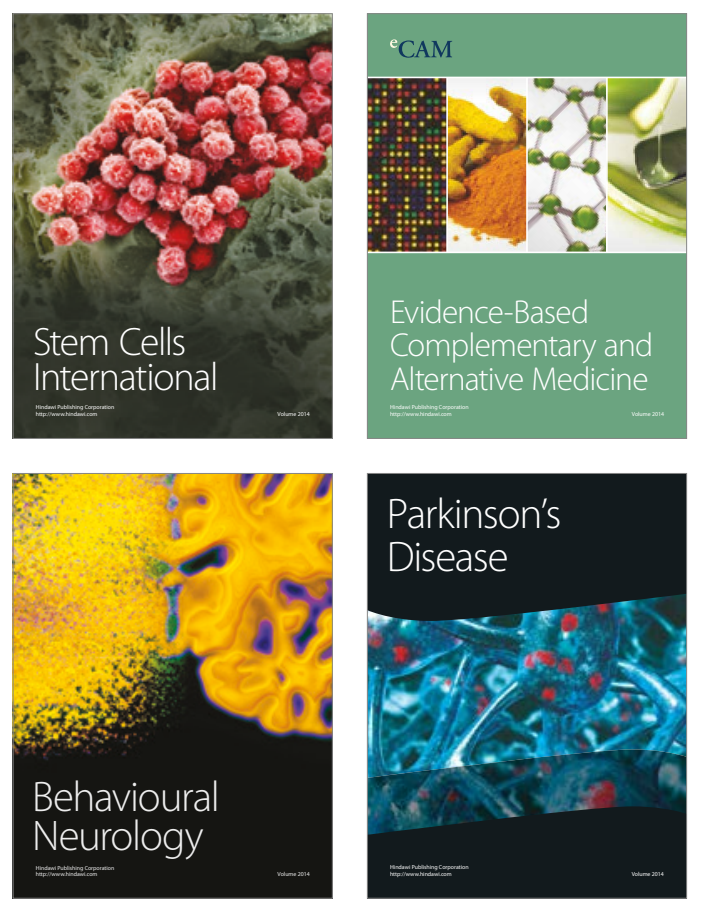
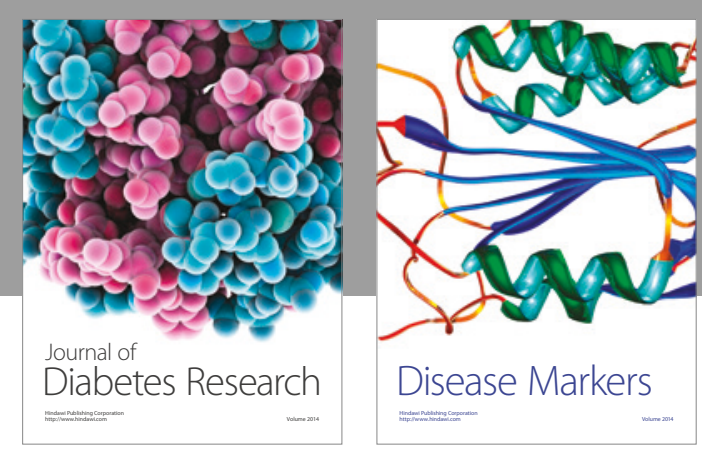

Disease Markers
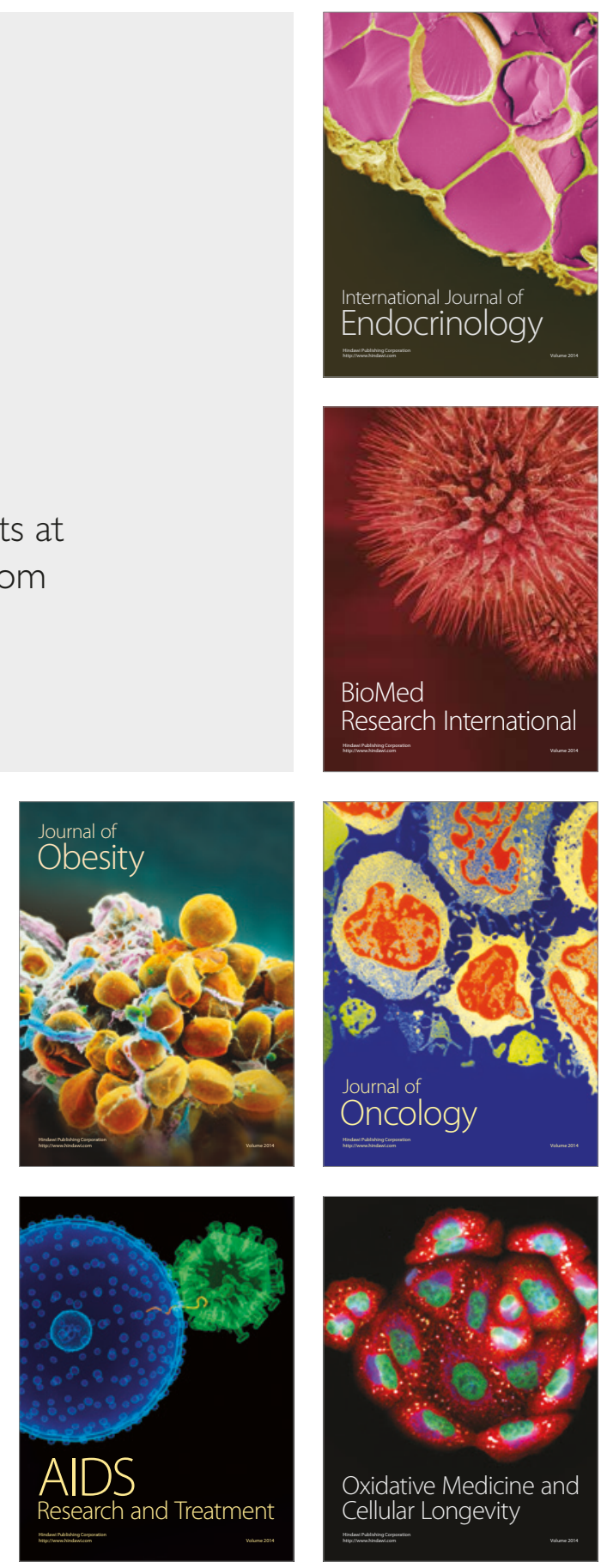